Article

\title{
Unexpected Frictional Behavior of Laser-Textured Hydrophobic Surfaces
}

\author{
Hiba Jendoubi, Olga Smerdova $(\mathbb{D}$ and Noël Brunetière * $\mathbb{D}$ \\ Institut Pprime, CNRS, Université de Poitiers, ISAE-ENSMA, 86000 Poitiers, France; \\ jendoubi.hiba@hotmail.com (H.J.); olga.smerdova@ensma.fr (O.S.) \\ * Correspondence: noel.brunetiere@univ-poitiers.fr; Tel.: +33-549-496-531
}

Citation: Jendoubi, H.; Smerdova, O.; Brunetière, N. Unexpected Frictional Behavior of Laser-Textured Hydrophobic Surfaces. Lubricants 2021, 9, 31. https://doi.org/10.3390/ lubricants 9030031

Academic Editor: Joerg Schille

Received: 19 January 2021

Accepted: 25 February 2021

Published: 6 March 2021

Publisher's Note: MDPI stays neutral with regard to jurisdictional claims in published maps and institutional affiliations.

Copyright: (c) 2021 by the authors. Licensee MDPI, Basel, Switzerland. This article is an open access article distributed under the terms and conditions of the Creative Commons Attribution (CC BY) license (https:/ / creativecommons.org/licenses/by/ $4.0 /)$.
Abstract: Hydrophobic surfaces can allow a liquid to slip over the surface and can thus reduce friction in lubricated contact working in a full film regime. Theory supports that the amount of slip can be increased if super-hydrophobic surfaces that are composed of a textured low surface energy material are used. In this work, polytetrafluoroethylene (PTFE) polymer samples were textured with a femto second laser to create super-hydrophobic surfaces by machining a hexagonal network of small circular holes with 10 and $20 \mu \mathrm{m}$ lattice sides. The frictional behavior of these surfaces was compared to the smooth PTFE samples. Surprisingly, the textured surfaces revealed higher friction coefficients than the smooth surfaces. This higher friction can be explained by a change of wetting regime due to high pressure in fluid and a possible generation of vortices in the cavities.

Keywords: surface texture; hydrophobic surface; friction; lubrication

\section{Introduction}

According to Holmberg and Erdemir [1], about 23\% of total global energy consumption is used to fight friction and wear. It is thus essential to propose solutions to reduce friction in machine components. In the case of lubricated contacts, surface texturing has proven to be efficient in several configurations to reduce friction [2,3]. For instance, by creating a network of shallow grooves on the sliding surface, the friction and temperature in a mechanical seal can be reduced by $50 \%[4,5]$.

Another solution to reduce friction was proposed by Spikes [6,7], which uses surfaces on which the lubricant fluid can slip, meaning that there is no adherence between the fluid and the surface. This slip is characterized by the slip length, which is defined as the distance between the surface and the point at which the relative fluid velocity would vanish. Salant and Fortier [8] showed theoretically that performance can be further improved by combining slip and and no-slip areas on the surface. The slip area lets more fluid enter the contact, as if the film was thicker. The heterogeneous slip/no slip bearing can thus be compared to a pocket or a step bearing. Several authors have since performed simulations to demonstrate the interest for this type of slip surface $[9,10]$. It is thus of importance to produce surfaces with slip that can be used in lubricated applications.

In their experimental work, Zhu and Granick [11] demonstrated that fluid can slip on a poorly wetted surface when its roughness height is lower than $6 \mathrm{~nm}$. For lower roughness level, the level of slip, which is characterized by the slip length, is controlled by chemical interactions between the fluid and the surface; as early shown by Schnell [12]. In the case of confined flows, roughness can allow slip of the fluid [13]. Using molecular dynamics, Huang et al. [14] found that the slip length is strongly correlated to the contact angle formed between the solid surface and a sessile water drop. The contact angle characterizes by a simple measurement the intensity of chemical interactions of water with the surface. The slip length is higher when the contact angle is higher. In both studies [11,14], the value of the slip length is a few tens of nanometers. According to theoretical work [6-10], these surfaces could provide lower friction level when used in 
lubricated contacts. These theoretical findings were confirmed for lubricated contacts submitted to low loads for which Choo et al. [15] found that a lower friction is obtained with hydrophobic surfaces (contact angle higher than $90^{\circ}$ ) than with hydrophilic surfaces (contact angle lower than $90^{\circ}$ ). Similarly, Guo et al. $[16,17]$ used several types of coating materials with different contact angles and showed that higher contact angle values lead to a behavior corresponding to slip of the lubricant on the coated surface. In the case of limit lubrication regime, the combination of a hydrophilic and a hydrophobic surfaces in a water lubricated contact is also efficient to reduce friction thanks to a hydration mechanism $[18,19]$. This very low film thickness lubrication corresponding to high loading is however not considered in the present work.

A much higher contact angle can be found on natural materials that are qualified as super-hydrophobic, such as the lotus leaf [20]. A texture is combined with a low surface energy material to give a Cassie Baxter state where the water drop lies on the top of the texture asperities [21]. Ou et al. [22] were able to significantly reduce water flow friction in micro-channels by using textured surface with a surface treatment to reduce surface energy. The slip length of these surfaces was about $20 \mu \mathrm{m}$. In 2006, Choi and Kim [23] created an artificial superhydrophobic surface composed of sharp silicon asperities covered with a layer of PTFE (PolyTetraFluoroEthylene). They tested the surfaces on a cone-and-plate rheometer and found slip length up to $20 \mu \mathrm{m}$ with water. If $30 \%$ of glycerin is added to water, the slip length could reach about $50 \mu \mathrm{m}$. This huge slip length value can be explained by the air trapped between the asperities, which reduces the apparent friction of the fluid on the surface. Different surface texture patterns were tested by Srinivasan et al. [24] on a plate-on-plate rheometer. A slip length of about $40 \mu \mathrm{m}$ was reached in the best case. A summary of the recent research on this topic and the slip length values obtained can be found in the paper of Solomon et al. [25].

Super-hydrophobic surfaces appear to be a very attractive solution to reduce friction in lubricated contacts thanks to slip length values that can be higher than the thickness of the lubricating film. However, in the literature, these surfaces were tested in microchannel flows or in a rheometer where the operating conditions are barely less severe than in lubricated contacts because there is no hydrodynamic pressure generation. In the present work, we designed super-hydrophobic surfaces by texturing flat PTFE samples with a femto second laser [26]. The surfaces were tested on a tribometer with different speeds and load conditions. We then compared the results to untextured surfaces to study the possible friction reduction provided by superhydrophobic textured surface in hydrodynamic lubrication regime.

\section{Materials and Methods}

\subsection{Samples}

A plate of $2 \mathrm{~mm}$ thickness of pure polytetrafluoroethylene PTFE (Approflon, France) was used to cut out circular samples with a manual press equipped with a cookie cutter of $10 \mathrm{~mm}$ in diameter. The samples were polished with an automatic polishing machine until $0.055 \mu \mathrm{m}$ arithmetic roughness $(\mathrm{S} a$ ) was obtained. After the polishing step, the samples were washed with ethanol in an ultrasonic bath for $15 \mathrm{~min}$ and then dried for $1 \mathrm{~h}$ in an oven at a temperature of $95{ }^{\circ} \mathrm{C}$. Contact angle measurements are then realized with a semi-automatic goniometer (Krüss DSA25) by posing a drop of $5 \mu \mathrm{L}$ on the sample surface. For each sample, contact angle measurements are done in five different areas. The values of contact angle were between $107^{\circ}$ and $112^{\circ}$ (see Figure 1), which is in agreement with the literature [27]. 


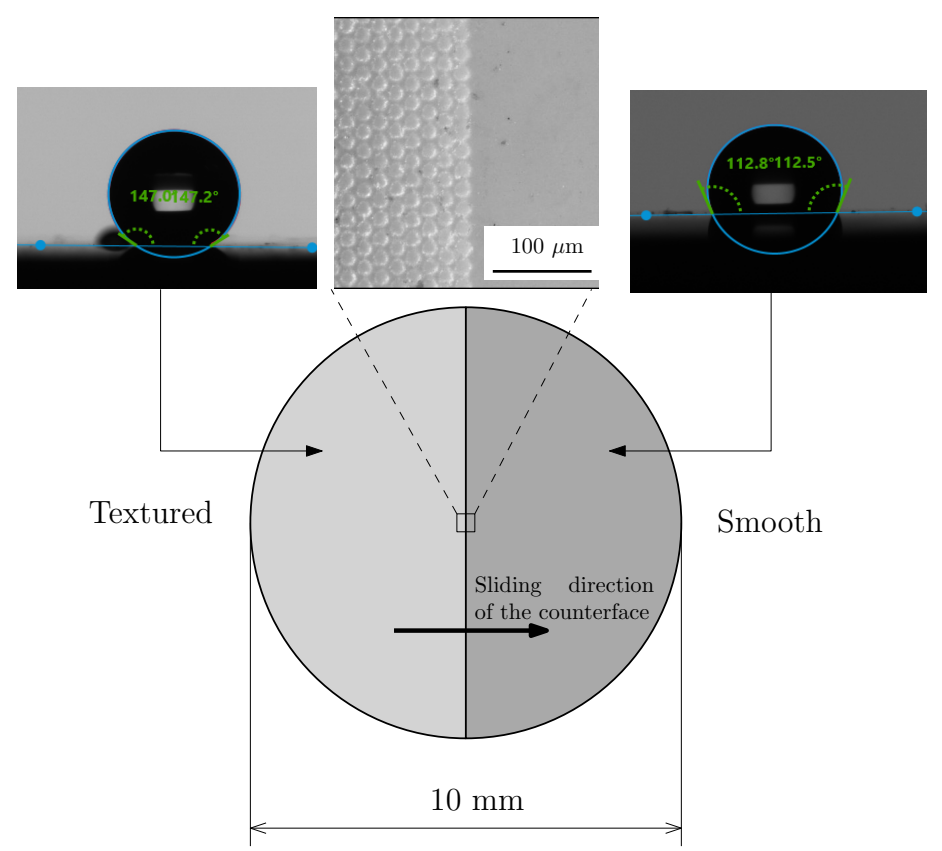

Figure 1. Example of half-textured sample with $20 \mu \mathrm{m}$ lateral texture size and sesille water drop images on the smooth and textured areas with respective contact angles $\left(112.8^{\circ}, 112.5^{\circ}\right)$ and $\left(147.0^{\circ}, 147.2^{\circ}\right)$.

\subsection{Surface Texturing}

To increase the hydrophobicity and reach a superhydrophobic state, the surfaces of the PTFE samples were textured. To allow a better mobility of the water on the surface, the objective was to obtain a Cassie Baxter wetting state, when the water drop lies on the top of the asperities, and avoid the Wenzel wetting state, when the water drop fully wets the asperities. Restrictions need to be imposed on the geometry of the pattern to ensure that the Cassie Baxter will be the most favorable energetic state [28]. Moreover, the texture must withstand mechanical shear loading during the friction tests. Thus, it was decided to create a network of cavities rather than the slender pillars or ridges that are used in the literature [25]. In this case, the contact angle $\theta_{\text {textured }}$ for the Cassie Baxter state satisfies the relation:

$$
\cos \theta_{\text {textured }}=f \cos \theta+f-1,
$$

where $f$ is the ratio of the area of the top surface (out of the cavities) to the total area and $\theta$ the contact angle for the smooth surface. To maintain a minimum material thickness between the cavities, the surface fraction $f$ cannot be lower than about 0.2 . If $\theta \simeq 110^{\circ}$, then a contact angle of $150^{\circ}$ is expected theoretically for a textured surface. The surface texture was manufactured with a femto-second laser (Manutech, France). The minimum texture lateral size that can be machined with the laser is $10 \mu \mathrm{m}$. A second set of samples with a lateral size of $20 \mu \mathrm{m}$ was also machined to obtain a better control of $f$ and of the shape of the cavities. Figure 2 shows the topography measured with a white light interferometer (Taylor Hobson Talysurf CCI 6000) on a sample with a $10 \mu \mathrm{m}$ pattern size and on a sample with a $20 \mu \mathrm{m}$ pattern size. The average depth of the pattern is about $5 \mu \mathrm{m}$ for the small texture and about $10 \mu \mathrm{m}$ for the large texture.

As proposed by Salant and Fortier [8], the samples were only partially textured to give a heterogeneous slip/no slip surface that will generate hydrodynamic lift between the sample and the counterface. Indeed, in hydrodynamic lubrication, the lubricant is drawn into the contact by the sliding movement of the surfaces. To maintain this lubrication regime, part of the surfaces must form a converging space so that the outlet section of the entrained fluid is smaller than the inlet. This design keeps the fluid film under pressure and creates a lift force that pushes the two surfaces apart. We were inspired by this principle by texturing only half of our samples. In this way, the lubricating film will pass through the textured part, in which the flow of the fluid will be facilitated by the slip, unlike the 
exit (the second half of the sample was kept smooth). This will create a lift force that will prevent contact of the two surfaces and will maintain a hydrodynamic lubrication regime throughout the friction test. The configuration of the half textured sample is presented in Figure 1. Three samples of each texture were manufactured and tested.

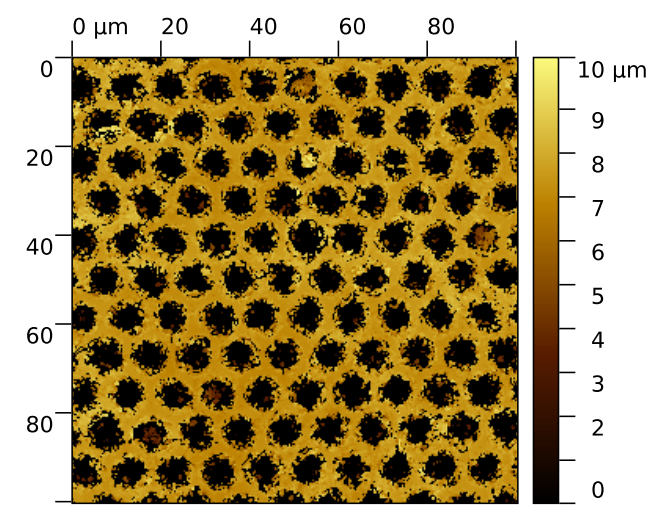

(a)

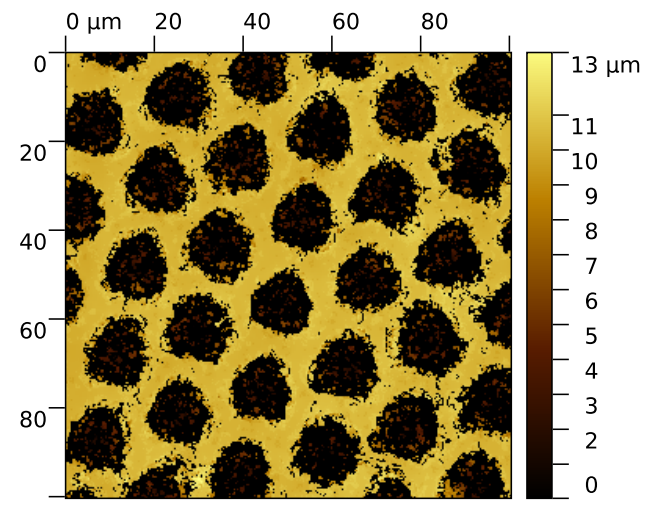

(b)

Figure 2. Surface topography of the samples measured by white light interferometry: (a) Sample with $10 \mu \mathrm{m}$ lateral texture size. (b) Sample with $20 \mu \mathrm{m}$ lateral texture size.

\subsection{Test Rig and Experimental Conditions}

The test rig that we used for these experiments is presented in Figure 3a) and schematised in Figure 3b). The tribometer is composed of an horizontal arm mounted on a frictionless air bearing allowing free vertical motion of the sample support. The polymer sample was glued to the arm of the tribometer. Before the glue dries, the PTFE disk was put into the contact with the counter-face, that is a smooth glass disk, to ensure perfect alignment of the sample and the glass. After drying, a controlled load was applied by means of a calibrated mass. Some water was poured on the glass disk to lubricate the contact. The textured part of the sample was placed upstream with respect to the direction of rotation of the disk, which allows the lubricant to pass through the textured part first. Once the contact is established, the glass disk is rotated by a motor mounted under the tribometer. A displacement sensor was mounted in front of a thin elastic beam that maintains the sample support. When the sliding starts, the elastic beam bends due to the friction resistance of the sample/disk contact. This bending displacement was measured by the displacement sensor and related to the frictional force of the contact by the stiffness of the setup measured prior to the experiments.

Several sliding conditions were tested by changing the sliding speed and normal load. The rotational speed $\omega$ of $100 \mathrm{rpm}, 150 \mathrm{rpm}$ and $200 \mathrm{rpm}$ and the calibrated masses from $10 \mathrm{~g}$ to $70 \mathrm{~g}$ were used. The radial position of the sample on the disk was $R_{d}=0.035 \mathrm{~m}$. The test conditions are summarized in Table 1 . The averaged loading pressured calculated from the applied mass and the sample area is also indicated.

Table 1. Test conditions.

\begin{tabular}{cc}
\hline Parameter & Value \\
\hline Sample material & PTFE \\
Rotating disk material & Glass \\
Lubricant & Water at $20^{\circ} \mathrm{C}$ \\
\hline Rotational speed $\omega(\mathrm{rpm})$ & $100,150,200$ \\
Applied mass $(\mathrm{g})$ & $10,30,50,70$ \\
Corresponding averaged pressure $(\mathrm{kPa})$ & $1.3,3.8,6.4,9.0$ \\
\hline
\end{tabular}


(a)
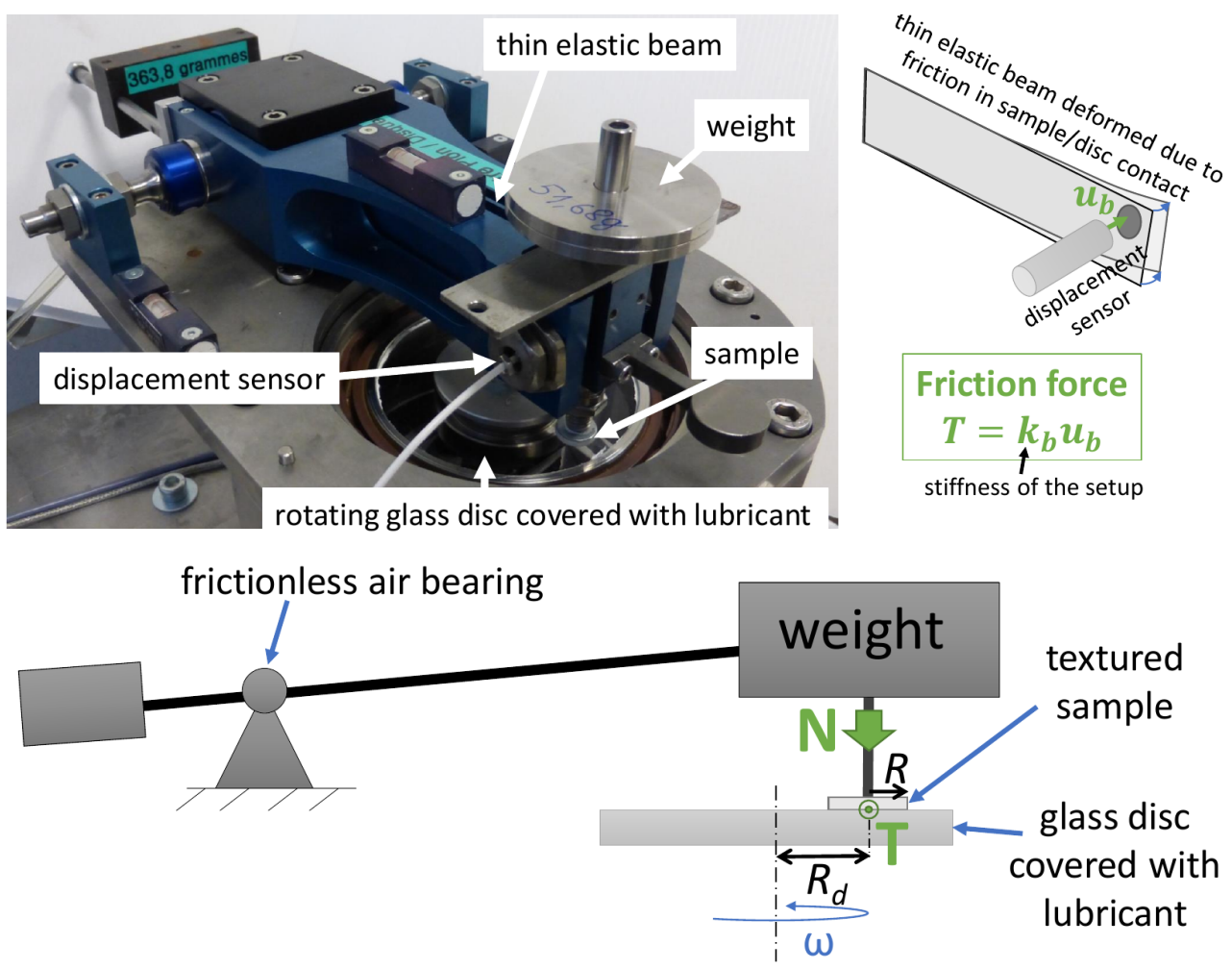

Figure 3. Presentation of the test rig: (a) Picture of the rig. (b) Principle of operation.

Each sample was used only once for each normal load and sliding speed combination to avoid any wear of the surface texture. Sliding duration was set at $30 \mathrm{~s}$. The friction coefficient presented later on was averaged on the last $25 \mathrm{~s}$.

\subsection{Simulation Tool}

A simulation tool was used to analyze the results of the test. The configuration of the studied problem is presented in Figure 4. The sample of radius $R$ is placed at distance $h_{0}$ from a flat surface moving along the $x$ direction. A possibility of integrating a flatness defect of the sample was introduced into the model by introducing two radii of curvature $R_{1}$ and $R_{2}$.

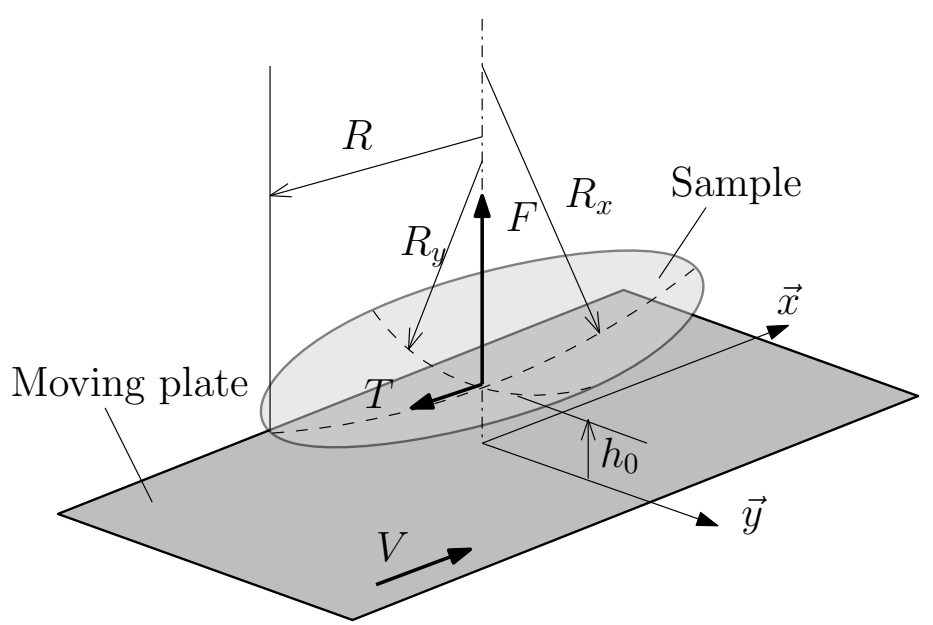

Figure 4. Configuration of the simulated problem. 
It is assumed that the fluid flow between the sample and the moving surface is governed by the Reynolds equation. In addition, a mass conserving cavitation model is used [29], leading to:

$$
F \frac{\partial}{\partial x}\left(\frac{h^{3}}{\mu} \frac{\partial D}{\partial x}\right)+F \frac{\partial}{\partial y}\left(\frac{h^{3}}{\mu} \frac{\partial D}{\partial y}\right)=6 V\left[\frac{\partial h}{\partial x}+(1-F) \frac{\partial h D}{\partial x}\right]
$$

where $h$ is the local film thickness and $\mu$ the fluid viscosity. $F$ is switch function and $D$ a universal variable that is related to the pressure $p$ of the fluid or its density $\rho$, depending if the fluid film is cavitated. In full film zones:

$$
F=1, \quad D=p, \quad \text { and } \quad \rho=\rho_{0}
$$

and in zones of cavitation:

$$
F=0, \quad D=\frac{\rho}{\rho_{0}}-1, \quad \text { and } \quad p=p_{c a v} .
$$

In these equations, $\rho_{0}$ is the liquid density and $p_{c a v}$ is the cavitation pressure. The Reynolds equation was discretized by the finite difference method and the system of equations was solved by a direct LU decomposition method for sparse matrices. Once the pressure in the fluid domain was calculated, the normal force $N$ and the friction force $T$ on the sample were calculated.

\section{Results}

\subsection{Sample Characterization}

The contact angle results for the textured surfaces are given in Table 2. A representative image of a water drop on a textured surface can be seen in Figure 1. As expected, the texture significantly increased the contact angle that was initially close to $110^{\circ}$ for the flat smooth PTFE surface. The contact angle of textured surfaces reached values close to, or higher than $150^{\circ}$. This value is considered to be the threshold, above which the behavior is superhydrophobic. Furthermore, the texture with a $20 \mu \mathrm{m}$ lateral size gave better results because of better precision of the laser machining and better control of the surface fraction $f$.

Table 2. Contact angle of water drops on texture surfaces.

\begin{tabular}{ccc}
\hline Sample & Spacing & Static Angle \\
\hline T10-1 & $10 \mu \mathrm{m}$ & $133 \pm 1^{\circ}$ \\
$\mathrm{T} 10-2$ & $10 \mu \mathrm{m}$ & $143 \pm 2^{\circ}$ \\
$\mathrm{T} 10-3$ & $10 \mu \mathrm{m}$ & $145 \pm 2^{\circ}$ \\
\hline $\mathrm{T} 20-1$ & $20 \mu \mathrm{m}$ & $147 \pm 2^{\circ}$ \\
$\mathrm{T} 20-2$ & $20 \mu \mathrm{m}$ & $142 \pm 2^{\circ}$ \\
$\mathrm{T} 20-3$ & $20 \mu \mathrm{m}$ & $153 \pm 3^{\circ}$ \\
\hline
\end{tabular}

In addition to the contact angle characterization, the global shape of the samples was measured with a 3D optical microscope (Alicona InfiniteFocus). It was then possible to calculate the principal radii of curvature $R_{1}$ and $R_{2}$ of the surfaces of all of the samples that we used. The results are presented in Figure 5. These results show that the samples were not perfectly flat, with a curvature radius of about $0.5 \mathrm{~m}$. This curvature induced a film thickness variation in the contact between the sample and the glass disk of several tens of microns. It is noteworthy that this value is significantly larger than the texture depth. 


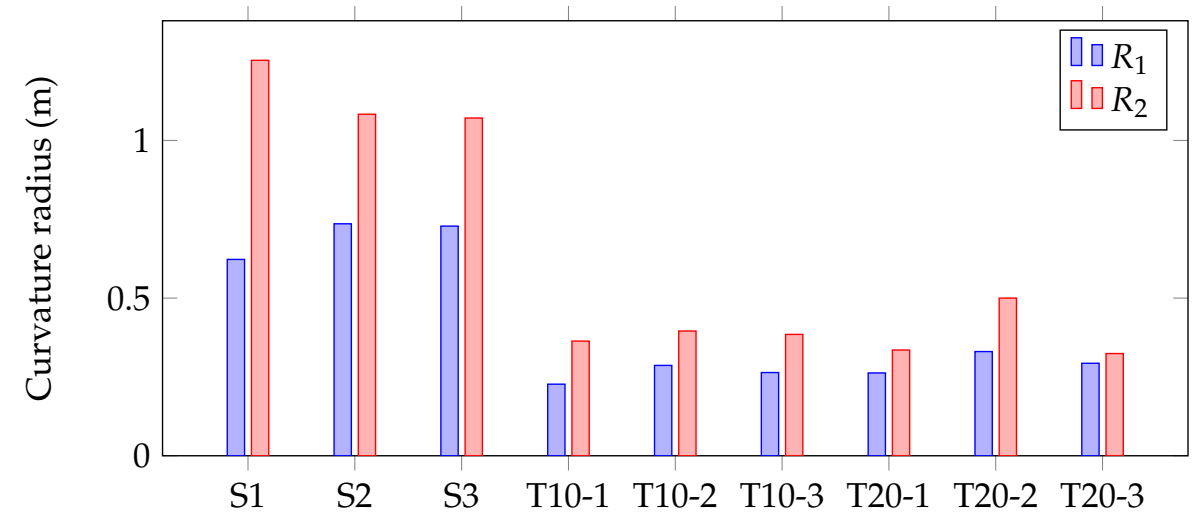

Figure 5. Principal curvature radii of the PTFE samples.

\subsection{Friction Tests}

Figure 6a presents typical tangential force signals as a function of the sliding distance for one sample of each type (smooth, textured with a lateral spacing of $10 \mu \mathrm{m}$ and textured with a lateral spacing of $20 \mu \mathrm{m}$ ). Even if the average value of the tangential force is stabilized, all the three signals exhibit some oscillations at three different frequency levels (see Figure 6b). The high frequency corresponds to noise on the signal. The oscillation with a period of about $0.07 \mathrm{~s}$ is the flexural natural frequency of the tribometer. The damping of the fluid film is not sufficient to vanish the vibration during the test duration (30 s). Finally an oscillation with a longer period probably induced by the revolution period of the disk (about $0.4 \mathrm{~s}$ ) is also viewable. The signals are averaged over $25 \mathrm{~s}$ to eliminate the effect of these time oscillations.

The results of the tests presented in Figure 7 are averaged over three samples of each category (smooth, textured with a lateral spacing of $10 \mu \mathrm{m}$ and textured with a lateral spacing of $20 \mu \mathrm{m})$. An error bar represents the variation among the three samples. The friction coefficient is the ratio of the friction force $T$ over the normal load $N$. It is presented as a function of the duty parameter $G$, which is defined in the following way:

$$
G=\frac{2 \mu V R}{N}
$$

where $V=R_{d} \omega$ is the linear sliding speed of the sample/disk contact.

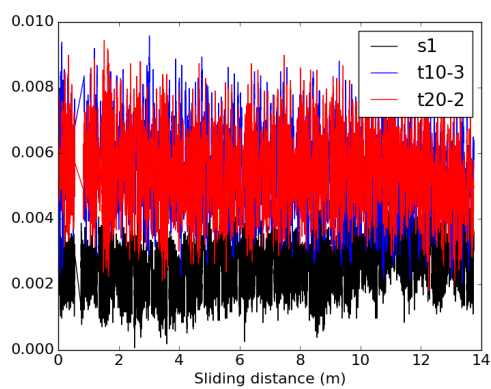

(a)

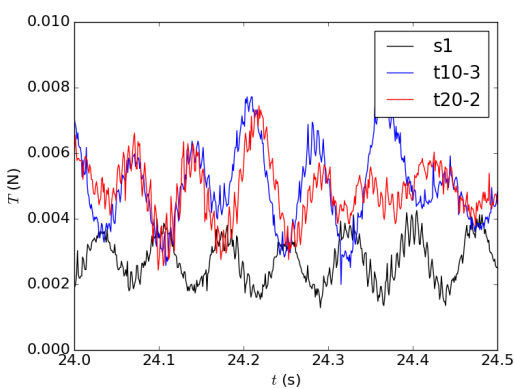

(b)

Figure 6. Measured tangential force as a function of the distance or time for three types of samples. The loading mass is $30 \mathrm{~g}$ and the rotational speed is $150 \mathrm{rpm}$. (a) Tangential force versus sliding distance for full test recording (b) Tangential force versus time during the last half second.

To highlight the evolution of the friction, a power law was fitted to each set of results. For each sample family, the opacity of the markers is proportional to the applied load making it possible to identify the effect of speed and load independently. Increasing the load at a given speed makes the friction lower while increasing the speed leads at a given load to a higher friction. For each family of samples, the friction increased with 
$G$, which means that the lubrication regime is mainly hydrodynamic. The variations in friction coefficient obtained for each category can be related to the difference in shape within the samples (see Figure 5). Unlike the expectations, the lowest friction was obtained with the smooth surfaces, while the $10 \mu \mathrm{m}$ spacing textured surfaces gave the highest friction value. Although the surface texturing was expected to allow slip of the fluid on the surface by increasing the contact angle, the results revealed that this was not the case. One possible explanation of this surprising finding is that the flatness defects of the sample had an influence on the results. This hypothesis will be discussed and verified in the following section.
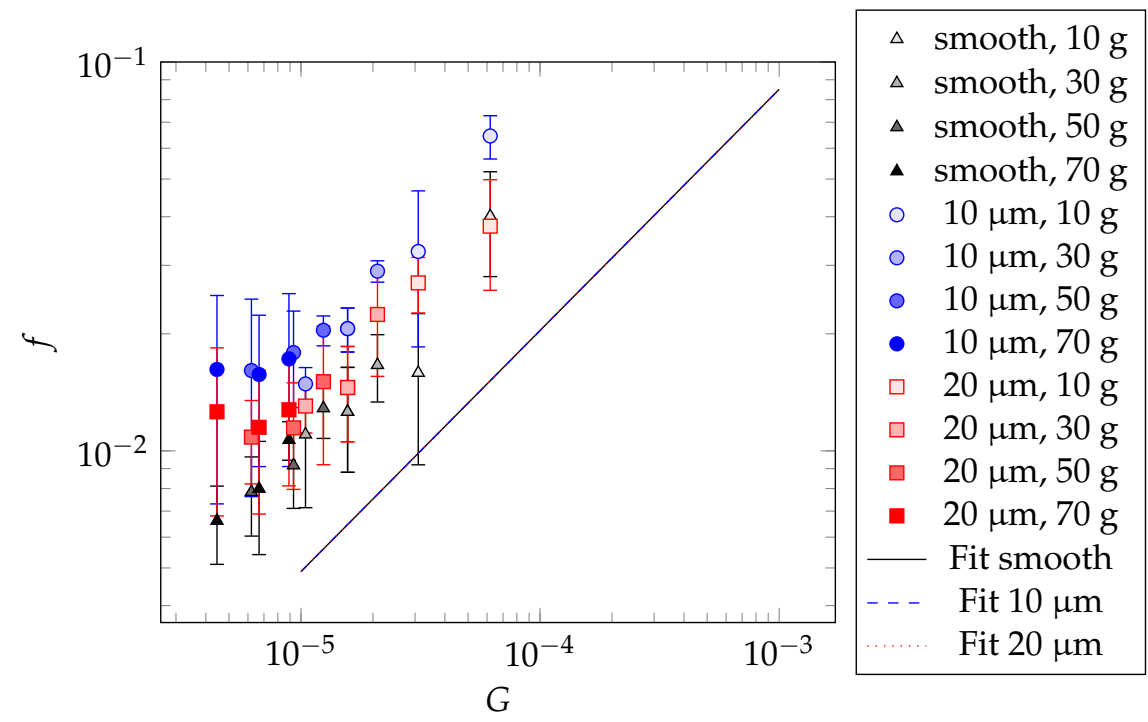

Figure 7. Measured friction coefficient as a function of the duty parameter $G$ for three type of samples. The values are averaged from three samples of each set and the error bar is the standard deviation. The opacity of the symbols is proportional to the load level. A power law fit curve is presented for each category.

\section{Discussion}

\subsection{Simulation of the Effect of Surface Curvature}

According to the lubrication theory, no hydrodynamic pressure can be generated between parallel flat surfaces. However, our results showed that a hydrodynamic lubrication regime can be reached with smooth samples. The hydrodynamic force is in fact generated by the surface residual curvatures due to the polishing process. In addition, this force depends on the surface curvature radii. This makes the comparison of the performance of different samples difficult because their surfaces are not identical. To highlight the effect of surface curvature, simulations were carried out on the configuration presented in Figure 4. The simulations were performed for different values of the curvature radii $R_{x}$ and $R_{y}$ of the sample and for different values of the central film thickness $h_{0}$. The parameters that were used in the simulations are given in Table 3.

Table 3. Parameters used for the simulation of Figure 8.

\begin{tabular}{cc}
\hline Parameter & Value \\
\hline Viscosity $\mu(\mathrm{Pa} \cdot \mathrm{s})$ & 0.001 \\
Averaged sliding speed $V\left(\mathrm{~m} \cdot \mathrm{s}^{-1}\right)$ & 1 \\
Sample radius $R(\mathrm{~m})$ & 0.005 \\
Curvature radius $R_{x}(\mathrm{~m})$ & $0.1-1$ \\
Curvature radius $R_{y}(\mathrm{~m})$ & $0.1-1$ \\
Domain size $(\mathrm{m})$ & 0.012 \\
Number of nodes & $256 \times 256$ \\
Cavitation pressure $p_{\text {cav }}(\mathrm{Pa})$ & 0 \\
\hline
\end{tabular}


The calculated friction coefficient $f=\frac{T}{N}$ was presented as a function of the duty parameter $G$ scaled by a shape factor:

$$
G^{*}=G \times\left(\frac{\sqrt{R_{x} R_{y}}}{R}\right)^{a}
$$

All of the simulation results with different surface curvatures were laid on the same line with the power law coefficient $a=0.355$, as can be seen in Figure 8 . When presented as a function of this modified duty parameter $G^{*}$, the friction coefficient is independent on the surface curvature. It is thus possible to fit the simulation results with a power law function:

$$
f=6.16 \times\left(G^{*}\right)^{0.62}
$$

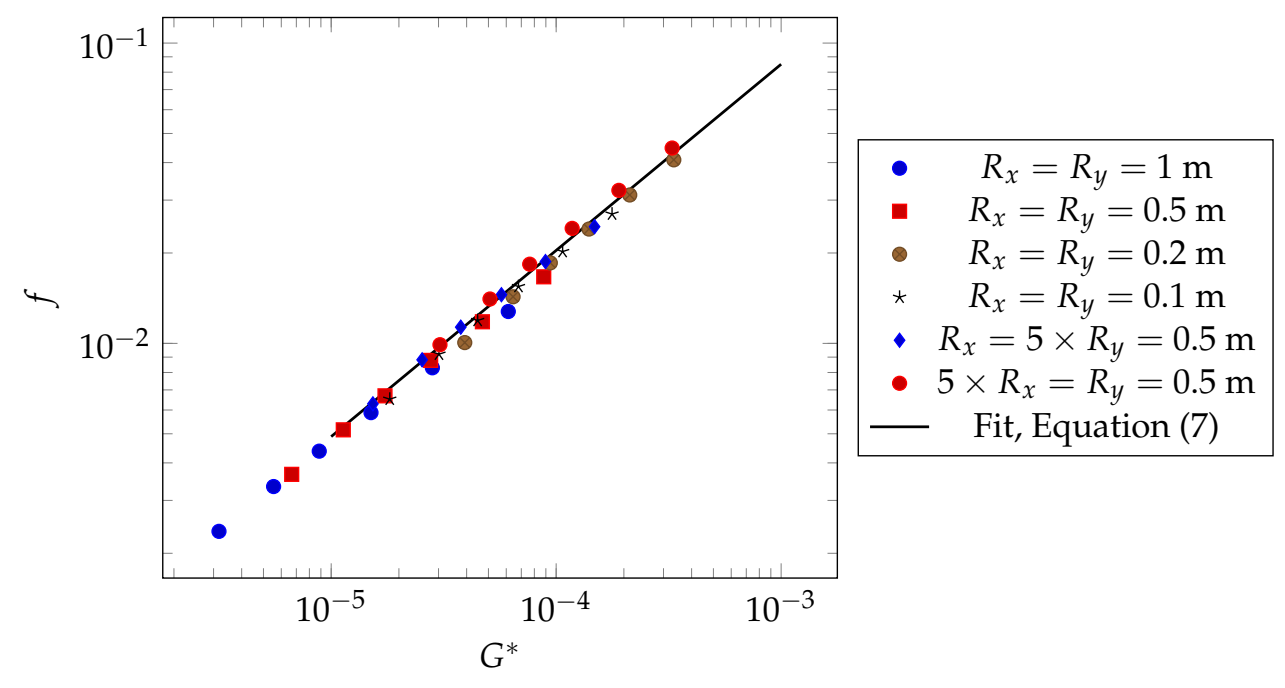

Figure 8. Simulated friction coefficient as a function of the modified duty parameter $G^{*}$ for different values of the surface curvature radii. A power law curve has been fitted on the results.

\subsection{Discussion of the Experimental Friction Results}

To remove the effect of the residual curvature of the samples, the friction coefficient is presented as a function of $G^{*}$ in Figure 9. The power law (7) obtained from simulations has also been added to the figure. It is interesting to see that the friction coefficient obtained with the smooth samples S2 and S3 is in good correlation with simulation law. Meanwhile, sample S1 gives a slightly lower friction. When the surfaces are textured, a significantly higher friction is obtained, except for a few conditions. This observation stands for the two configurations of texture. Although an increase of the hydrophobicity of the surfaces due to texturing was expected to provide a better sliding of the water and to reduce friction, the opposite is obtained here. This means that the slip of water does not take place.

An analysis of the results of the literature $([13,22,23,25])$ where a friction decrease was obtained thanks to surface texture enhancing hydrophobicity shows that in all cases the texture was composed of pillars or ridges parallel to the flow direction. Even if an amount of air is maintained between the texture, the fluid flow was facilitated between the ridges and pillars. In our case, the texture is composed of cylindrical cavities. Even if these cavities are efficient in increasing hydrophobicity and can maintain the air trapped in the cavities, there is no easy path for the water flow.

In addition, during the simulations performed to obtain the results of Figure 8, the maximum fluid pressure calculated in the fluid film varied between about $6.5 \mathrm{kPa}$ and $270 \mathrm{kPa}$, depending on the value of $G^{*}$. This pressure would impact the interface between water and the air trapped in the cavities, as shown in Figure 10. The curvature radius of the spherical interface is given by the Laplace equation: 


$$
R_{c}=\gamma \times\left(\frac{2}{p_{\ell}-p_{g}}\right)
$$

where $\gamma\left(=0.071 \mathrm{~N} \cdot \mathrm{m}^{-1}\right)$ is the water surface tension, $p_{\ell}$ is the liquid pressure and $p_{g}$ is the gas pressure. The maximum pressure differential that can withstand the interface depends on the diameter of the hole and the value of the contact angle $\theta$ (see Figure 10). It is thus possible to calculate a critical diameter $d_{c}$ of a hole from the fluid pressure resulted from the simulations:

$$
d_{c}=-\gamma \times\left(\frac{4 \cos \theta}{p_{\ell}-p_{g}}\right)
$$

Using the pressure calculated in the simulations, it is found that $d_{c}$ is in the range 0.36 $\mu \mathrm{m}$ for the highest pressure value to $15 \mu \mathrm{m}$ for the lowest pressure. The size of the texture used in the experiments is thus not small enough to ensure the stability of the water-air interface for all of the experimental conditions. It is thus possible for the water to fill the cavities, either partially or completely.

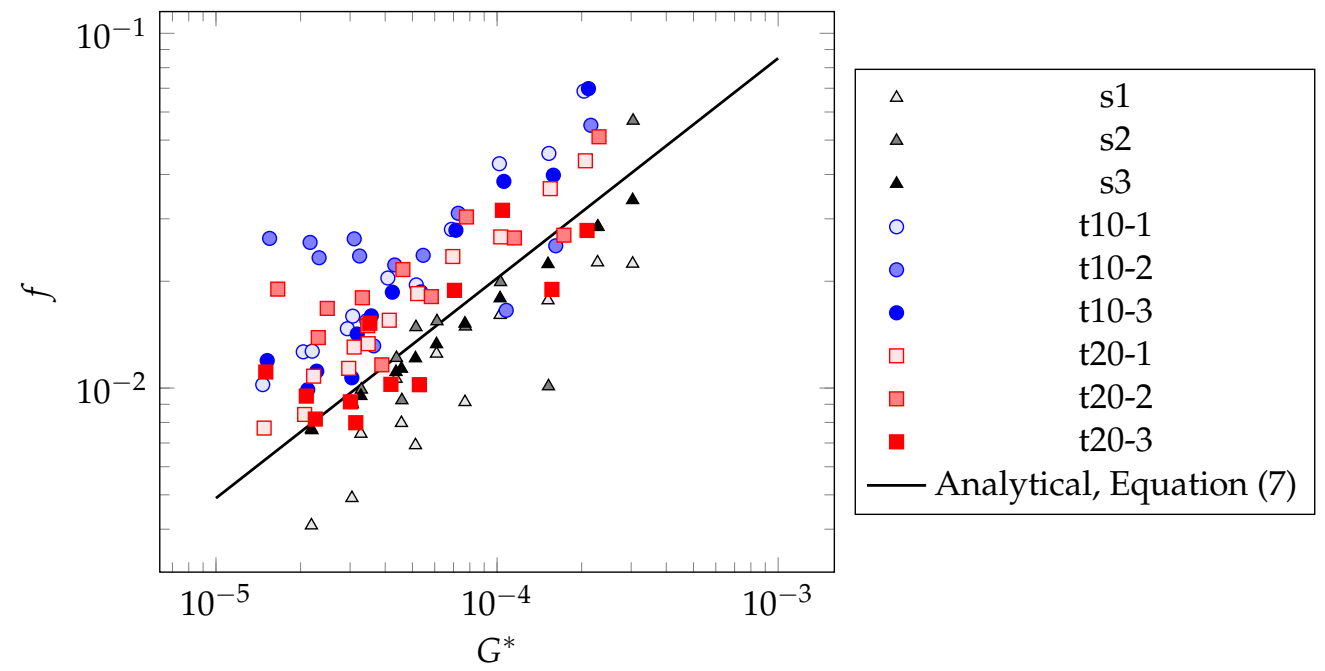

Figure 9. Friction coefficient as a function of the modified duty parameter $G^{*}$-Experimental results and comparison to the numerically fitted curve.

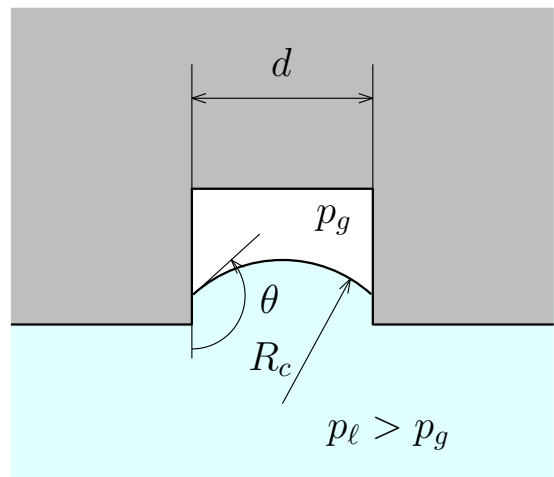

Figure 10. Effect of the liquid pressure on the air water interface shape.

Several papers $[30,31]$ dedicated to the simulation of fluid flow over textured surfaces with a shape ratio (texture depth to texture width) similar to our case have demonstrated that flow vortices can be observed in the cavities, even at a very low Reynolds number. More particularly, Mateescu et al. [30] showed that the viscous dissipation in these vortices leads to an increase in drag or friction even for Reynolds number values tending to zero. The most important parameter for drag increase was shown to be the ratio of cavities depth to film thickness. Given that it is possible for water to partially or completely fill 
the cavities due to the hydrodynamic pressure in the liquid, the air-water interface can be destabilized thus creating water cavities (Figure 11). The results of Mateescu et al. [30] suggest that some vortices can appear in our samples and increase the friction. In this case, the texture would work as a labyrinth seal, contrary to what was expected.

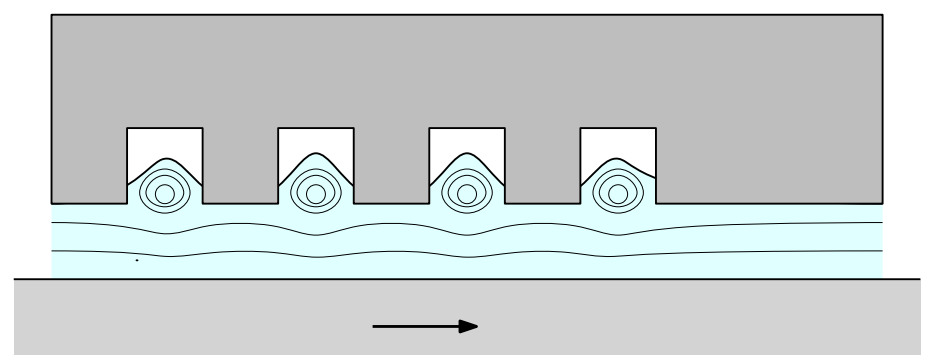

Figure 11. Vortices in the cavities increasing the sliding friction.

\section{Conclusions}

In this paper, the possibility to reduce friction in a hydrodynamic lubrication regime with superhydrophobic textured surfaces was experimentally investigated. PTFE disks were mechanically polished and textured with a femto second laser to create a hexagonal network of cylindrical cavities on a half of the sample's surface. The results showed that with cavities spacing of 10 and $20 \mu \mathrm{m}$, the hydrophobic character of the samples was increased with a contact angle up to $153^{\circ}$. Friction tests were conducted on these samples and compared to the results of smooth samples of the same material. In contrast to what was expected, these tests showed that the texture increased the friction coefficient. The numerical simulations with Reynolds flow showed that the observed effect could not be explained by the imperfect curvature of the sample surfaces. However, comparing our results with the literature provided a plausible explanation in that the fluid partially or completely filled the cavities due to high pressure in the contact. In addition, the literature supports the hypothesis that vortices could appear in the cavities, leading to an increase in friction due to the viscous dissipation. Indeed, the texture in our samples was applied by creating holes instead of the pillars used by other researchers. Our texture pattern was designed for better mechanical resistance of the surfaces to shear due to friction. However, it seems that this type of texture modifies the flow compared to the pillar texture, thus increasing the friction. This phenomenon can be avoided by using smaller cavities (sub-micron scale), which would imply the need to change the machining process.

Author Contributions: Conceptualization, O.S. and N.B.; methodology, H.J., O.S. and N.B.; software, H.J. and N.B.; validation, H.J., O.S. and N.B.; formal analysis, H.J., O.S. and N.B.; investigation, H.J.; writing and original draft preparation, H.J. and N.B.; writing, review and editing, H.J., O.S. and N.B.; visualization, H.J., O.S. and N.B.; supervision, O.S. and N.B.; project administration, N.B.; funding acquisition, N.B. All authors have read and agreed to the published version of the manuscript.

Funding: This work was supported by the French government program "Investissements d'Avenir" (LABEX INTERACTIFS, reference ANR-11-LABX-0017-01).

Institutional Review Board Statement: Not applicable.

Informed Consent Statement: Not applicable.

Data Availability Statement: Not applicable.

Acknowledgments: This work pertains to French government program "Investissements d'Avenir" (EUR INTREE, reference ANR-18-EURE-0010).

Conflicts of Interest: The authors declare no conflict of interest. 


\begin{abstract}
Abbreviations
The following abbreviations are used in this manuscript:

PTFE PolyTetreFluoroEthylene
\end{abstract}

\title{
References
}

1. Holmberg, K.; Erdemir, A. Influence of tribology on global energy consumption, costs and emissions. Friction 2017, 5, 263-284. [CrossRef]

2. Gropper, D.; Wang, L.; Harvey, T.J. Hydrodynamic lubrication of textured surfaces: A review of modeling techniques and key findings. Tribol. Int. 2016, 94, 509-529. [CrossRef]

3. Rosenkranz, A.; Grützmacher, P.G.; Gachot, C.; Costa, H.L. Surface Texturing in Machine Elements-A Critical Discussion for Rolling and Sliding Contacts. Adv. Eng. Mater. 2019, 21, 1900194. [CrossRef]

4. Etsion, I.; Halperin, G. A Laser Surface Textured Hydrostatic Mechanical Seal. Tribol. Trans. 2002, 45, 430-434. [CrossRef]

5. Dingui, K.; Brunetière, N.; Bouyer, J.; Adjemout, M. Surface Texturing to Reduce Temperature in Mechanical Seals. Tribol. Online 2020, 15, 222-229. [CrossRef]

6. Spikes, H. The Half-wetted Bearing. Part 2: Potential Application in Low Load Contacts. IMechE Part J J. Eng. Tribol. 2003, 217, 15-26. [CrossRef]

7. Spikes, H. The Half-wetted Bearing. Part 1: Extended Reynolds Equation. IMechE Part J J. Eng. Tribol. 2003, 217, 1-14. [CrossRef]

8. Salant, R.; Fortier, A. Numerical Analysis of a Slider Bearing with a Heterogeneous Slip/No-Slip Surface. Tribol. Trans. 2004, 47, 328-334. [CrossRef]

9. Wu, C.; Ma, G.; Zhou, P.; Wu, C. Low friction and high load support capacity of slider bearing with a mixed slip surface. J. Tribol. 2006, 128, 904-907. [CrossRef]

10. Fatu, A.; Maspeyrot, P.; Hajjam, M. Wall slip effects in (elasto) hydrodynamic journal bearings. Tribol. Int. 2011, 44, 868-877. [CrossRef]

11. Zhu, Y.; Granick, S. Limits of the Hydrodynamic No-Slip Boundary Condition. Phys. Rev. Lett. 2002, 88, 106102. [CrossRef] [PubMed]

12. Schnell, E. Slippage of water over nonwettable surfaces. J. Appl. Phys. 1956, 27, 1149-1152. [CrossRef]

13. Kunert, C.; Harting, J. Roughness Induced Boundary Slip in Microchannel Flows. Phys. Rev. Lett. 2007, 99, 176001. [CrossRef]

14. Huang, D.M.; Sendner, C.; Horinek, D.; Netz, R.R.; Bocquet, L. Water Slippage versus Contact Angle: A Quasiuniversal Relationship. Phys. Rev. Lett. 2008, 101, 226101. [CrossRef]

15. Choo, J.; Spikes, H.; Ratoi, M.; Glovnea, R.; Forrest, A. Friction reduction in low-load hydrodynamic lubrication with a hydrophobic surface. Tribol. Int. 2007, 40, 154-159. [CrossRef]

16. Guo, L.; Wong, P.; Guo, F. Correlation of contact angle hysteresis and hydrodynamic lubrication. Tribol. Lett. 2015, 58, 45. [CrossRef]

17. Guo, L.; Wong, P.; Guo, F. Identifying the optimal interfacial parameter correlated with hydrodynamic lubrication. Friction 2016, 4, 347-358. [CrossRef]

18. Lin, W.; Klein, J. Control of surface forces through hydrated boundary layers. Curr. Opin. Colloid Interface Sci. 2019, 44, 94106.10.1016/j.cocis.2019.10.001. [CrossRef]

19. Rosenhek-Goldian, I.; Kampf, N.; Klein, J. Trapped Aqueous Films Lubricate Highly Hydrophobic Surfaces. ACS Nano 2018, 12, 10075-10083. [CrossRef] [PubMed]

20. Bhushan, B. Biomimetics: Lessons from Nature - An Overview. Philos. Trans. R. Soc. A 2009, 367, 1445-1486. [CrossRef] [PubMed]

21. Law, K.Y.; Zhao, H. Surface Wetting-Characterization, Contact Angle, and Fundamentals; Springer: London, UK, 2016.

22. Ou, J.; Perot, B.; Rothstein, J.P. Laminar drag reduction in microchannels using ultrahydrophobic surfaces. Phys. Fluids 2004, 16, 4635-4643. [CrossRef]

23. Choi, C.H.; Kim, C.J. Large Slip of Aqueous Liquid Flow over a Nanoengineered Superhydrophobic Surface. Phys. Rev. Lett. 2006, 96, 066001. [CrossRef]

24. Srinivasan, S.; Choi, W.; Park, K.C.; Chhatre, S.S.; Cohen, R.E.; McKinley, G.H. Drag reduction for viscous laminar flow on spray-coated non-wetting surfaces. Soft Matter 2013, 9, 5691-5702. [CrossRef]

25. Solomon, B.R.; Khalil, K.S.; Varanasi, K.K. Drag reduction using lubricant-impregnated surfaces in viscous laminar flow. Langmuir 2014, 30, 10970-10976. [CrossRef]

26. Küper, S.; Stuke, M. Ablation of polytetrafluoroethylene (Teflon) with femtosecond UV excimer laser pulses. Appl. Phys. Lett. 1989, 54, 4-6. [CrossRef]

27. Dann, J. Forces involved in the adhesive process: I. Critical surface tensions of polymeric solids as determined with polar liquids. J. Colloid Interface Sci. 1970, 32, 302-320. [CrossRef]

28. Bittoun, E.; Marmur, A. Optimizing Super-Hydrophobic Surfaces: Criteria for Comparison of Surface Topographies. J. Adhes. Sci. Technol. 2009, 23, 401-411. [CrossRef]

29. Payvar, P.; Salant, R. A Computational Method for Cavitation in a Wavy Mechanical Seal. J. Tribol. 1992, 114, 199-204. [CrossRef] 
30. Mateescu, G.; Ribbens, C.J.; Watson, L.T.; Wang, C.Y. Effect of a sawtooth boundary on Couette flow. Comput. Fluids 1999, 28, 801-813. [CrossRef]

31. Arghir, M.; Roucou, N.; Helene, M.; Frene, J. Theoretical Analysis of the Incompressible Laminar Flow in a Macro-Roughness Cell. J. Tribol. 2003, 125, 309-318. [CrossRef] 